\title{
An improved RST approach for timely alert and Near Real Time monitoring of oil spill disasters by using AVHRR data
}

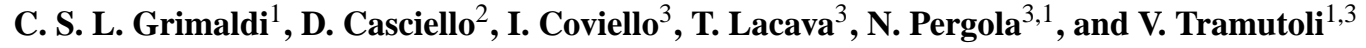 \\ ${ }^{1}$ Department of Engineering and Physics of the Environment (DIFA), University of Basilicata, Potenza, Italy \\ ${ }^{2}$ Unità Operativa Territorio ed Attività Produttive, ARPA Lombardia, Milano, Italy \\ ${ }^{3}$ Institute of Methodologies for Environmental Analysis (IMAA), National Research Council, Tito Scalo, Italy
}

Received: 3 November 2010 - Revised: 22 December 2010 - Accepted: 4 January 2011 - Published: 9 May 2011

\begin{abstract}
Information acquired and provided in Near Real Time is fundamental in contributing to reduce the impact of different sea pollution sources on the maritime environment. Optical data acquired by sensors aboard meteorological satellites, thanks to their high temporal resolution as well as to their delivery policy, can be profitably used for a Near Real Time sea monitoring, provided that accurate and reliable methodologies for analysis and investigation are designed, implemented and fully assessed.

In this paper, the results achieved by the application of an improved version of RST (Robust Satellite Technique) to oil spill detection and monitoring will be shown. In particular, thermal infrared data acquired by the NOAA-AVHRR (National Oceanic and Atmospheric Administration-Advanced Very High Resolution Radiometer) have been analyzed and a new RST-based change detection index applied to the case of the oil spills that occurred off the Kuwait and Saudi Arabian coasts in January 1991 and during the Lebanon War in July 2006.

The results obtained, even in comparison with those achieved by other AVHRR-based techniques, confirm the unique performance of the proposed approach in automatically detecting the presence of oil spill with a high level of reliability and sensitivity. Moreover, the potential of the extension of the proposed technique to sensors onboard geostationary satellites will be discussed within the context of oil spill monitoring systems, integrating products generated by high temporal (optical) and high spatial (radar) resolution satellite systems.
\end{abstract}

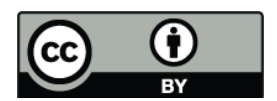

Correspondence to: C. S. L. Grimaldi (grimaldi@imaa.cnr.it)

\section{Introduction}

Sea oil pollution can derive from different sources. Accidental release of oil into the oceans caused by natural hazards (hurricanes, landslides, earthquakes) or "human errors" (tanker collisions, shipwrecks, platform accidents) have remarkable ecological impact on maritime and coastal environments (Schmidt-Etkin, 2011). The events which have affected the Gulf of Mexico in the last five years are a clear demonstration of the relevance of these sources and of their serious effects on the natural environment. In 2005 the Katrina and Rita hurricanes hit oil and gas infrastructures off US-coasts, causing the destruction of more than 113 platforms and the release into the sea of more than 17000 barrels of crude oil (Hogarth, 2005; Pine, 2006; Cruz and Krausmann, 2008, 2009). In 2010 the explosion of the platform Deepwater Horizon caused the discharge of about 5 million barrels ( 550 million litres) in the ocean for three months (Mitsch, 2010). While man-made events could probably be prevented by acting in a different way both before and after the accidents, it is more difficult to face natural hazard, which are often unpredictable, both in their appearance and in their consequences.

Nonetheless, besides big events, oil spill has a global impact on the marine environment, as the main pollution sources are operational discharges from tankers (i.e. oil dumped during cleaning operations, ITOPF, 2010).

Satellite remote sensing, thanks to global coverage and continuity of observations, might contribute to the mitigation of oil spill environmental impact, provided that reliable and effective detection techniques are developed and that relevant information and products are timely delivered and made available. 
Nowadays, the most preferred satellite instruments for oil spill detection are SAR (Synthetic Aperture Radar) sensors (Liu et al., 2000; Brekke and Solberg, 2005; Kostianoy et al., 2006; Ferraro et al., 2007; Jha et al., 2008), mainly due to their all-weather and all-time capabilities (Fingas and Brown, 1997, 2000) and to their suitable spatial resolution. Unfortunately, the actual operational use of SAR sensors (TerraSAR, Radarsat, Envisat-ASAR, etc.) for a timely detection of oil spill at the global scale is currently restricted by their relatively high cost and their low revisiting time at middle latitude. More recently, this limitation has been significantly reduced by the full completion (since October 2010) of the COSMO-Skymed (Constellation of Small Satellites for Mediterranean basin Observation) constellation of four SAR satellites that can guarantee, for a selected portion of the globe, a refresh time up to $12 \mathrm{~h}$ (ASI, 2007; e-GEOS, 2010). However, several issues regarding cost and an effectively global delivery policy of such data still remain open and might limit their use in an operational context. On the other hand, COSMO-Skymed being a dual mission, issues related to possible conflicts between the two use modes (civil and military), should be also taken carefully into account when an operational service is aimed at. It is also to be considered that, due to its intermittent way of working, SAR is suitable for systematic monitoring activities at their best nominal temporal resolution only for limited areas of the world.

In addition, there are also some applicability limits of the present SAR-based techniques to be taken into account. First of all, SARs cannot detect oil spill presence when wind speed is lower than $3 \mathrm{~m} \mathrm{~s}^{-1}$ or higher than $6 \mathrm{~m} \mathrm{~s}^{-1}$ (Fingas and Brown, 1997). Moreover, there are other natural phenomena that reduce backscattered signal reaching the sensor, producing an oil spill similar signal (look-alikes). These phenomena include natural films (biogenic oil or algal bloom), grease ice, wave shadow behind land or structures or rain cells (Fingas and Brown, 1997; Brekke and Solberg, 2005 and references herein reported).

For all the above-mentioned reasons, passive optical sensors, on board meteorological satellites, may represent a suitable SAR alternative and/or a useful complement for oil spill detection and monitoring. Their high temporal resolution, in fact (from several hours to a few minutes, depending on the characteristics of the platform/sensor), together with a general quick and no-cost access to their data, are particularly useful for studying such events, characterised by very high space-time dynamics. In this case, time is a crucial factor in preventing/limiting environmental damages oil spills may produce on both maritime and coastal domains. Besides, weather satellites generally provide a synoptic view, covering large areas in short times by means of wide swath images. On the other hand, the main limitation of optical sensors is related to cloud cover; clouds, in fact, are not transparent in the IR region, and they do prevent the observation of the Earth's surface from space.
However, so far, optical satellite data has found a poor application in such a field, mainly for the lack of data analysis techniques suitable for an automatic oil spill detection. The few methods up to now proposed are only able to manually and interactively localize the presence of an already known oil spill, often requiring the human intervention of an expert operator (Cross, 1992; Tseng and Chiu, 1994; Borzelli et al., 1996; Hu et al., 2003; Howari, 2004; Shi et al., 2007). In particular, techniques based on Thermal (TIR) Infrared records (Cross, 1992; Borzelli et al., 1996) exploit oil and water different thermal inertia in order to map spill sea pollution. Oil thermal inertia, in fact, is lower than seawater one, so that oil-polluted areas usually show higher Brightness Temperature (BT) than seawater in TIR images collected in the daytime while the opposite is true at night-time (Fingas and Brown, 1997, 2000).

However, sea surface temperature and corresponding emitted radiation have a space-time dynamics (due to bathymetry, water circulation, etc.) much greater than that due to the contrast between oil-polluted and not-polluted seawater, which cannot be taken into account (producing false positive proliferation) by the above-mentioned (fix threshold, single image based) methods. For this reason, they remain suitable only for mapping oil spill events in a limited zone where the presence of oil is already known. Hence, they cannot be used for monitoring wide areas and giving a first (and timely) alarm on the occurrence of the spill.

In recent times, an innovative technique based on the general RST - Robust Satellite Techniques, (Tramutoli, 2005, 2007) - approach, originally named RAT - Robust AVHRR Technique - (Tramutoli, 1998), has been proposed (Casciello et al., 2007a, b, 2011; Grimaldi et al., 2009) which, instead, allows the automatic detection of the presence of oil spill over the sea surface, minimizing the "false-positive" at the same time. To the scope TIR data acquired by NOAA-AVHRR (National Oceanic and Atmospheric Administration - Advanced Very High Resolution Radiometer) in channels 4 and 5 (respectively $10.3-11.3 \mu \mathrm{m}$ and $11.5-12.5 \mu \mathrm{m}$ ) have been used. Thanks to its short revisiting time (less than $6 \mathrm{~h}$, considering present NOAA satellites constellation), and low data acquisition cost, and despite its moderate/coarse spatial resolution (1.1 km at nadir), AVHRR data have demonstrated usefulness in the context of a Near Real Time disaster monitoring system, such as that devoted to manage oil spill risks. Up to now, only daytime acquisition has been considered because of the relatively low contrast between oil and seawater which makes oil spill identification during night-time difficult.

The results obtained by applying such a technique for the analysis of the spill occurred during the "Gulf War" off the Kuwait and Saudi Arabian coasts in January 1991 will be shown in this paper. The performances obtained by the proposed methodology will be discussed and analyzed, also for comparison with those obtained by another AVHRRbased approach. Recent improvements of the proposed 
technique, developed to increase RST sensitivity toward oil spill of small size/low intensity, will be also presented and analyzed. In addition, results achieved analyzing the Lebanon oil spill event that occurred in July 2006, will also be shown and discussed. Finally, possible advantages arising from the implementation of this technique on MODIS (Moderate Resolution Imaging Spectroradiometer) data, acquired from the two EOS (Earth Observing System) satellites Terra and Aqua, as well as on MSG-SEVIRI (Meteosat Second Generation - Spinning Enhanced Visible and Infrared Imager) records, will be discussed.

\section{Methodology}

The RST approach (Tramutoli, 2005, 2007) exploits the analysis of long-term multi-temporal satellite records in order to obtain a former characterization of the measured signal at pixel level, in terms of expected value and natural variability. It provides further identification of signal anomalies by an automatic, unsupervised change detection step. RST has already successfully found application in other fields of environmental monitoring, like forest fire detection (Cuomo et al., 2001; Mazzeo et al., 2007; Baldassarre et al., 2009), floods (Lacava et al., 2005, 2006, 2007, 2009; 2010a, b; Faruolo et al., 2009), and volcanic eruptions (Pergola et al., 2001, 2004a, b, 2009; Bonfiglio et al., 2005; Filizzola et al., 2007) monitoring, seismic areas investigation (Tramutoli et al., 2001, 2005; Di Bello et al., 2004; Filizzola et al., 2004; Corrado et al., 2005; Genzano et al., 2007, 2009; Lisi et al., 2010), etc. Briefly, the technique is based on the preliminary characterization of AVHRR radiances in normal (i.e. unperturbed) conditions. This characterization is done by analyzing a homogeneous, multi-year, data-set of colocated satellite images collected at the same acquisition time and the same month of year of the image to be processed. On this basis, an Absolutely Local Index of Change of Environment (ALICE) is computed as follows:

$\otimes_{V}(x, y, t)=\frac{\left[\mathbf{V}(x, y, t)-\boldsymbol{\mu}_{V}(x, y)\right]}{\sigma_{V}(x, y)}$

where $\mathbf{V}(x, y, t)$ is the satellite signal presently measured at pixel centred at coordinates $(x, y)$ on the image at hand (acquired at time $=t$ ) $\mu_{V}$ and $\sigma_{V}$ are, respectively, the temporal average and standard deviation of such a signal, computed for the same pixel analyzing multi-year historical time-series of satellite records acquired under the same observational conditions (same month of the year, same hour of the day). Therefore, $\otimes_{V}(x, y, t)$ gives a measure of the excess (or deficiency) of the current signal, $\mathbf{V}(x, y, t)$, compared with its historical mean value and weighted by its historical variability at each considered location. In general, the signal $\mathbf{V}(x, y, t)$ is the measurement achieved in a single, specific spectral channel but it can also be a combination of different bands (Tramutoli, 1998). The robustness of this approach is intrinsic, because the higher the variability $\sigma_{V}(x, y)$ of the signal is, the harder it will be to achieve high values of $\otimes_{V}(x, y, t)$ reducing, in this way, the occurrence of spurious site/local effects and, consequently, the problem of false alarms.

As stated above, thermal IR data may be useful for oil spill detection thanks to the thermal inertia contrast between oil and surrounding water. Thus, for oil spill detection and monitoring purposes, the suggested signal to be investigated $(\mathbf{V}(x, y, t))$ is the brightness temperature $\mathbf{T}(x, y, t)$ measured in AVHRR TIR channels $4(10.3-11.3 \mu \mathrm{m})$ or $5(11.5-$ $12.5 \mu \mathrm{m}$ ) and the Eq. (1) becomes as follow:

$\otimes_{T}(x, y, t)=\frac{\left[\mathbf{T}(x, y, t)-\boldsymbol{\mu}_{T}(x, y)\right]}{\boldsymbol{\sigma}_{T}(x, y)}$

We expect to measure, in fact, in presence of spill, higher values of $\otimes_{T}(x, y, t)$ during daytime, the opposite during night. Some possible limits of such an indicator may be the year-to-year changes of the signal and/or seasonal time-drifts which usually affect near-surface temperatures on a regional scale.

In order to overcome such a potential problem, in a further implementation (Casciello et al., 2007a, b, 2011), oil spill detection was obtained by using a tailored RST-based index, the RETIRA (Robust Estimator of TIR Anomalies) index (Tramutoli et al., 2005):

$\otimes_{\Delta T}(x, y, t)=\frac{\left[\mathbf{\Delta} \mathbf{T}(x, y, t)-\boldsymbol{\mu}_{\Delta T}(x, y)\right]}{\boldsymbol{\sigma}_{\Delta T}(x, y)}$

where the signal, $\mathbf{V}(x, y, t)$, in Eq. (3) is represented by $\Delta \mathbf{T}(x, y, t)=\mathbf{T}(x, y, t)-<T(t)>$, the brightness temperature difference between the current $\mathbf{T}(x, y, t)$ value, measured, in the AVHRR TIR band considered (band 4 at $10.3-11.3 \mu \mathrm{m}$ or 5 at $11.5-12.5 \mu \mathrm{m})$, at location $(x, y)$ and its spatial average $\langle T(t)\rangle$, computed in place on the image at hand considering only cloud-free pixels located over sea locations within the investigated area. Results obtained by using such an index have already shown its potential for an automatic, unsupervised and robust identification of oil spill presence with a reliability of $100 \%$ over the full scene (no false alarms) in different geographic areas and also several days apart from the event, when the increasing of emulsion effects may generally limit the efficiency of other detection schemes (Casciello et al., 2007a, b, 2011).

In this work, to further enhance the sensitivity of the RETIRA index towards slicks of "small" intensity (both in terms of size and/or thickness), a new RST-based index is proposed. It is based again on RETIRA (Eq. 3) but the quantity $\langle T(t)\rangle$ is not calculated over the whole sea portion of the scene, but now computed for a box of $N \times N$ sea pixels around the $(x, y)$ location. Therefore, in this advanced configuration the following index will be computed: 


$$
\begin{aligned}
\otimes_{\Delta \mathrm{Tbox}}(x, y, t, N) \\
=\frac{\left[\boldsymbol{\Delta} \mathbf{T}_{\text {box }}(x, y, t, N)-\boldsymbol{\mu}_{\Delta \mathrm{Tbox}}(x, y, N)\right]}{\sigma_{\Delta \mathrm{Tbox}}(x, y, N)}
\end{aligned}
$$

where $\boldsymbol{\Delta} \mathbf{T}_{\text {box }}(x, y, t, N)$ is the difference between the signal value $\mathbf{T}(x, y, t)$ observed at location $(x, y)$, and the spatial average $\langle T(t, N)\rangle$ of the surrounding $N \times N-1$ pixels within the $N \times N$ box centred on the $(x, y)$ pixel, considering only cloud-free sea pixels. Such a sort of "contextual" RETIRA index (hereafter reported as RETIRA box $_{\text {), shown }}$ for the first time in this work, should further improve sensitivity toward very low intensity signals, such as those related to illicit tanker cleaning procedures. Taking into account all the sea pixels during the computation of $<$ $T(t)>$ (especially when an area of great extension in NS direction are considered) may, in fact, negatively affect the computation of $\langle T(t)\rangle$ values and, consequently, $\Delta \mathbf{T}, \mu_{\Delta T}$ and $\sigma_{\Delta T}$, for several reasons: (i) when $T(t)$ is computed on a very large area, $\mathbf{\Delta} \mathbf{T}(x, y, t)=\mathbf{T}(x, y, t)-<$ $T(t)>$ will range an extended set of values (moving from low to high latitudes) and consequently $\sigma_{\Delta T}$ will locally assume higher values reducing the overall RST sensitivity; (ii) a possible asymmetric cloud distribution over the scene could reduce the value of $\langle T(t)\rangle$, facilitating the occurrence of false positive, (when clouds are masking the warmer part of the scene) or increasing missing alarms (if clouds dominate the colder part of the scene). These circumstances may affect both technique reliability and sensitivity, limiting in particular the possibility of detecting small perturbing signals, such as those related to illicit discharge procedures. On the other hand, considering only the nearest-neighbour pixels during the $\langle T(t)\rangle$ computation, all the above mentioned limitations should be removed. Moreover, the expected reduction of $\sigma_{\Delta \text { Tbox }}$ could make an increase of sensitivity toward very low intensity signals possible, that may be associated, again, to illicit tanker cleaning procedures. For this work window size has been chosen with $N=9$ in order to be small enough to strongly reduce the above-mentioned large scale effects and wide enough to be used also for broad spills.

\section{Implementation: "Gulf War" and "Lebanon War" oil spills}

The accident occurred during the "Gulf War" off the Kuwait and Saudi Arabian coasts in January 1991, brought serious environmental damages to major portions of the Middle East (WCMC, 1991; Tseng and Chiu, 1994).

On 21 January 1991, a few days after the coalition forces launched an air campaign against Iraq, Iraqi military forces in Kuwait opened valves at the Sea Island oil terminal near Kuwait city and released large quantities of crude oil into the Gulf, as an act of environmental warfare. The polluted area had an extension of $144 \mathrm{~km}^{2}$ southeast of Kuwait city

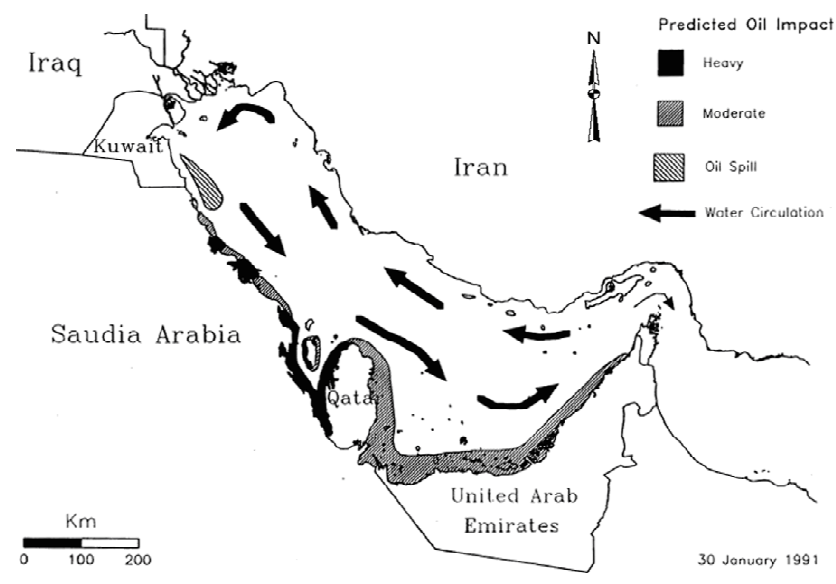

Fig. 1. "Gulf War" oil spill localization (WCMC, 1991).

(Fig. 1). Because of cyclonic currents, the oil moved southward and began to accumulate on the North Coast of Saudi Arabia, endangering the fragile costal zones and mangrove forests and destroying wildlife habitats (WCMC, 1991).

For the computation of the AVHRR reference fields, a historical data set of all AVHRR images available in a temporal range of ten years, from 1989 to 1999, covering the studied region, during the same month of January and in the same temporal range (10:30-11:30 GMT, Local Time $=\mathrm{GMT}+3)$, was processed. A Region Of Interest (ROI) of $512 \times 512$ pixels was extracted from each satellite scene and re-projected in the same Geographic projection (Lat-Lon - WGS84). The ROI is centred at $32^{\circ}$ LAT N, $52^{\circ}$ LONGE. Temporal average $\left(\boldsymbol{\mu}_{T} ; \boldsymbol{\mu}_{\Delta T} ; \boldsymbol{\mu}_{\Delta \mathrm{Tbox}}\right)$ and standard deviation $\left(\sigma_{T} ; \sigma_{\Delta T} ; \sigma_{\Delta \text { Tbox }}\right)$ reference fields were computed on this area using the above constructed data-sets for AVHRR TIR channels 4 and 5 .

Thus, the three above defined indexes were computed and applied, at pixel level, to all the cloud-free AVHRR scenes acquired during the spill event.

Moreover, in order to evaluate the reliability of the achieved results, a comparison with the oil spill maps obtained using the fix threshold, AVHRR-based, technique proposed by Cross (1992) was performed.

In order to test the RST performances in different geographic and observational conditions, also the oil spill event that occurred in July 2006, during the Lebanon war has been analyzed. On 13 and 15 July 2006 the oil-fuelled power plant of Jiyyeh, located directly on the coastline approximately $30 \mathrm{~km}$ south of Beirut, was hit by bombs. Part of the storage tanks caught fire and were burning for several days. Approximately 30000 tons of heavy fuel oil was spilled into the Mediterranean Sea as a result of the blast (REMPEC, 2006; UNEP, 2006). 

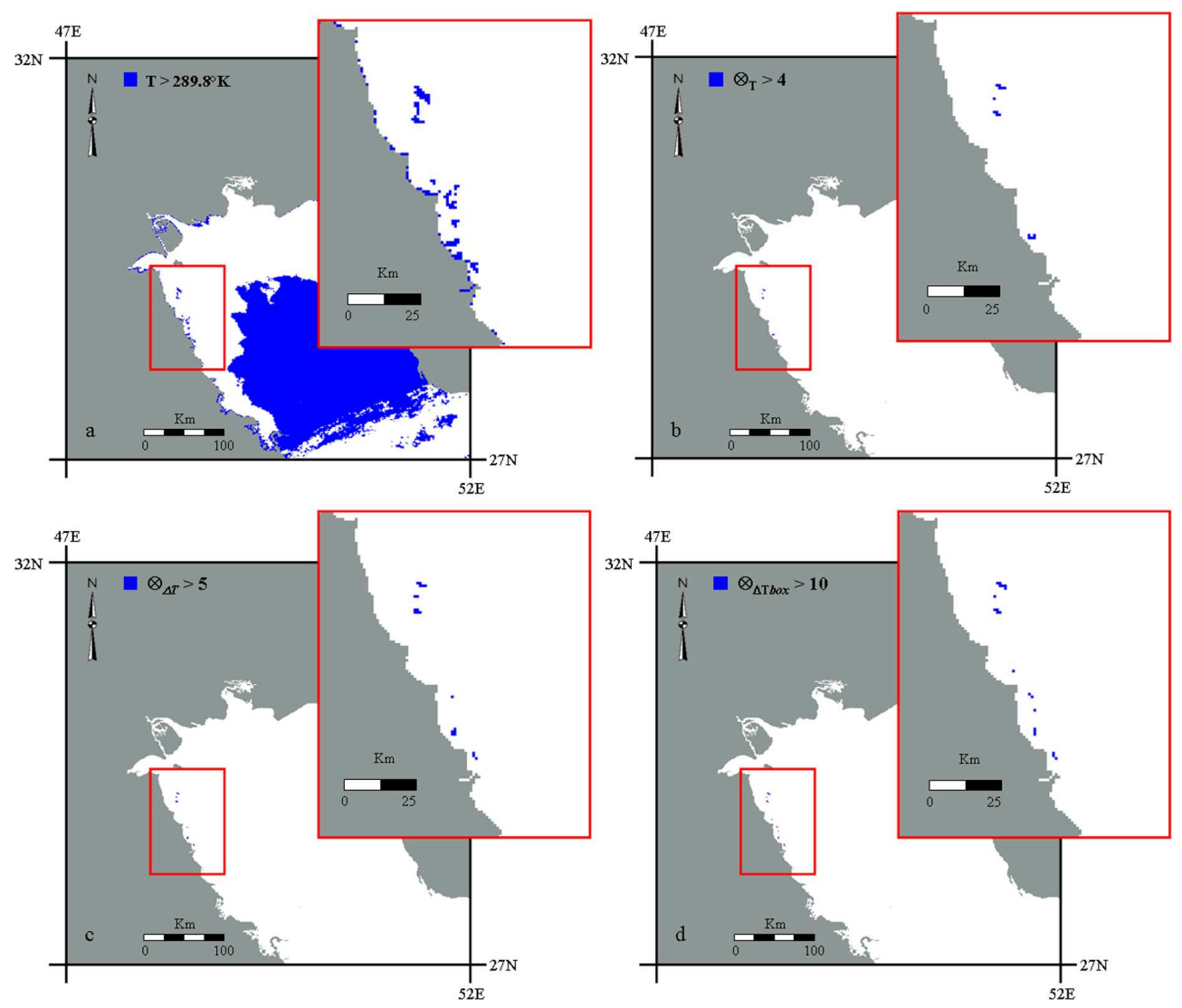

Fig. 2. Comparison between results achieved by: (a) Cross' (1992) technique, (b) ALICE, (c) RETIRA and (d) RETIRA box index for the AVHRR image (channel 4) of 24 January 1991 at 10:31 GMT (13:31 LT). Anomalous pixels are depicted in blue, land is masked in gray and the sea is white. Areas indicated by red boxes are magnified in the corresponding insets.

For the computation of the AVHRR reference fields for the Lebanon War event, the same procedure already applied for the previous test case has been used. In particular, a historical data set of about 80 images, all acquired in the period from 2000 to 2006 during the month of July and in the same temporal range (10:30-13:30 GMT), have been processed. The ROI (Region of interest) was centred for this event at $34^{\circ} \mathrm{N} 34.5^{\circ} \mathrm{E}$.

\section{Results}

In this section, the results achieved applying the RST approach, in its different versions, on the studied oil spill event are shown (Figs. 2 and 3). In particular, the RST results are also compared with those achieved by Cross (1992), which, to enhance the contrast between the oil-polluted areas and clean sea, applied interactively established thresholds to the radiances measured in the AVHRR channel 4, identifying oil spill where $T_{4}>T_{\max }$, being $T_{4}$ the brightness temperature measured in AVHRR channel 4 and $T_{\max }$ the "a posteriori" selected threshold. For the sake of brevity, the results obtained by applying the above mentioned indexes for two event images (21 January at 10:31 GMT and 29 January at 11:24 GMT), are shown only for the AVHRR channel 4, as the results achieved in channel 5 are very similar. For these two images, the $T_{\max }$ identified by Cross (1992) were $289.8 \mathrm{~K}$ for the first one and $287.6 \mathrm{~K}$ for the second image. In making and analysing comparisons, it should be stressed again that the RST-based techniques instead, do not need an operator, automatically generating oil spill maps by means of a completely unsupervised processing scheme, within minutes after the acquisition of raw AVHRR data.

Looking at Figs. 2 and 3, it is possible to observe as the presence of oil spill is detected with a reliability of $100 \%$ over the whole scene (i.e. no false alarms) by RST, in all its versions, for both the analyzed images at very high index values corresponding to very high $\mathrm{S} / \mathrm{N}$ ratio levels. High $\mathrm{S} / \mathrm{N}$ values indicate high confidence levels in oil spill detection. As soon as an oil spill detection has been performed "for sure" (as in this case) by RST, it is possible to zoom in on the affected area and perform a more detailed mapping of the spill, investigating spatial distribution of signal anomalies with lower intensities associated to spills of different thickness/size and/or at different levels of emulsion in seawater (Casciello et al., 2011). 

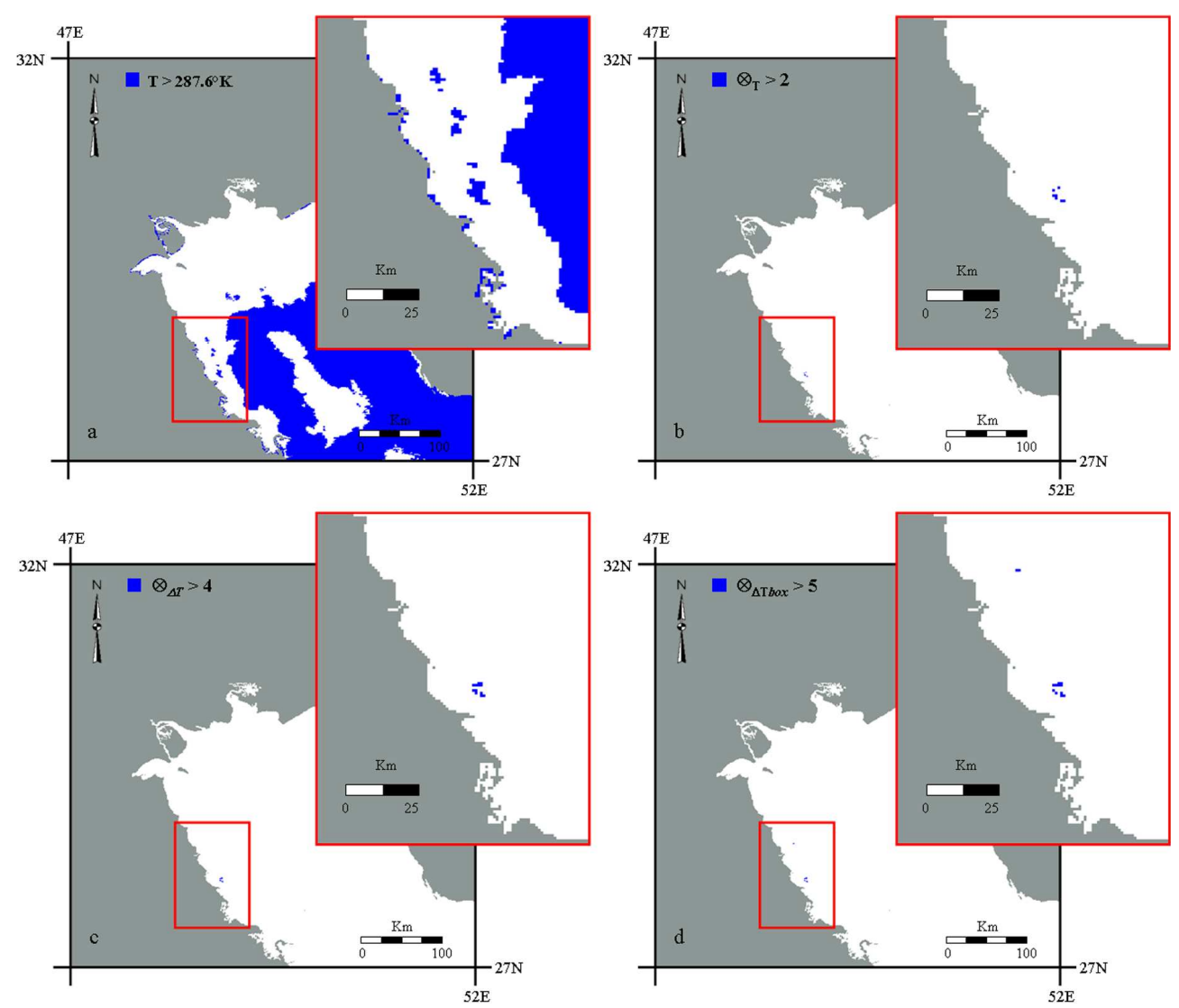

Fig. 3. As Fig. 2 for the AVHRR image of 29 January 1991 at 11:24 GMT (14:24 LT).

In details, the analysis of Figs. 2 and 3 confirms, first of all, that the oil spill had a southward motion along the Arabian coasts caused by the marine currents, as reported by the oil drift models achieved from in-situ observations (Daniel and Potevin, 1992; Proctor et al., 1994). Moreover, looking at Figs. 2a and 3a, the problems arising if a fix threshold approach is used for automatic detection purposes (Cross, 1992) are evident: in fact, together with an accurate mapping of spills, a huge amount of false positive anomalies are detected (see the large areas at the image centre which are also detected as polluted). The normal thermodynamics of sea surface and related sea currents cannot be taken into account by the fix threshold techniques. For this reason they, may be used only for "a posteriori" analyses, when notice of the event occurrence as well as approximate positions of polluted areas are already known. Such a problem does not affect RST: in fact the impact of "site" effects is automatically removed, considering the "history" of each pixel of the scene. Therefore, RST identifies only significant changes in the space-time domain and may be profitably used for automatic detection of unknown events (neither in time nor in space) .

Looking at the RST results, shown in Figs. 2b, c, d and $3 \mathrm{~b}, \mathrm{c}, \mathrm{d}$, it appears clear, as the ALICE, RETIRA and RETIRA $A_{\text {box }}$ indexes are all able to correctly identify spill presence over the scene in both the AVHRR images with a total absence of false alarms. As expected, a progressive improvement in sensitivity of the proposed technique is recognizable moving from ALICE to RETIRA till RETIRA $A_{\text {box }}$ (see also Table 1). The advantages in using the ALICE index (Figs. $2 b$ and $3 b$ ) with respect to a fix threshold technique are quite evident (Figs. 2a and 3a) and have been already discussed above. Further improvements achieved by using the RETIRA index (Figs. 2c and 3c) instead of the ALICE index can be summarized as follow: (i) an increase of the relative intensity at which the oil spill identification has been done ( $\mathrm{S} / \mathrm{N}$ from 4 to 5 in the first image, from 2 to 4 in the second one) without false positive; ii) an increase of the maximum $\mathrm{S} / \mathrm{N}$ ratio related to the event: for 24 January 1991 we move from a maximum ALICE index of 7.87 to a maximum RETIRA index of 11.13 , while in the image of 29 January 1991 from 2.33 to 5.08 for the same quantities; (iii) an increase of the number of anomalous pixels suitable for generating an oil spill alarm: from 15 to 21 for the first image, from 7 to 12 for the second one.

Finally, in the last step (Figs. $2 \mathrm{~d}$ and $3 \mathrm{~d}$ ), the advantages presented above have been significantly enhanced by using

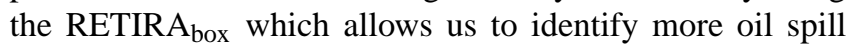


Table 1. Main RST results achieved analyzing the Gulf War oil spill event.

\begin{tabular}{lccc}
\hline & ALICE $\otimes_{T}$ & ${\text { RETIRA } \otimes_{\Delta T}}$ & RETIRA $_{\text {box }} \otimes_{\Delta T \text { Tbox }}$ \\
\hline 24 January 1991 & & & \\
\hline Detection for sure (S/N level) & 4 & 5 & 10 \\
Number of Oil Spill Pixels & 15 & 21 & 34 \\
Max S/N value & 7.87 & 11.13 & 33.02 \\
\hline 29 January 1991 & & & 5 \\
\hline Detection for sure (S/N level) & 2 & 4 & 14 \\
Number of Oil Spill Pixels & 7 & 12 & 13.01 \\
Max S/N value & 2.33 & 5.08 & \\
\hline
\end{tabular}

pixels at higher $\mathrm{S} / \mathrm{N}$ values than RETIRA. We move from 21 RETIRA anomalous pixels in the image of 24 January to 34 pixels of RETIRA $A_{\text {box }}$ and from 12 to 14 pixels in the image of 29 January. Moreover, also the RETIRA $A_{\text {box }} \mathrm{S} / \mathrm{N}$ level at which a detection "for sure" is achieved increases in both the images (up to 10 in the first image, 5 in the second one) as well as the maximum $\mathrm{S} / \mathrm{N}$ over the scene (33.02 for 24 January, 13.01 for 29 January). In Table 1 a summary of the results obtained by applying the three RST based indexes is reported.

These results highlight the continuous improvements achieved by applying the RST approach in different and advanced configurations. In particular, moving from ALICE to RETIRA $A_{\text {box }}$, saving full reliability, a progressive increase in sensitivity is obtained with a consequently increased potential in detection capability toward signals of lower intensity, possibly related to small size/thickness events including illegal spill discharges, that are the main cause of hydrocarbon sea pollution and also more difficult to detect. Besides, the increase of the $\mathrm{S} / \mathrm{N}$ associated to the detected anomalies enables, around the pixels detected "for sure", a more detailed mapping of oil slick structure when an extended range of lower RETIRA $\mathrm{box}_{\text {index values (higher oil }}$ slick thickness are expected in correspondence with a higher RETIRA $_{\text {box }}$ values) are explored (Fig. 4).

Thus, we can affirm that the RST technique saves its detection capability in all the proposed versions also several days apart from the event, when the thermal contrast of polluted zones becomes less distinguishable due to the effect of emulsions between oil and seawater and to the reduction of oil thickness (lower relative intensity of detected anomalies in the image of 29 January, using all the three indexes, are due to these phenomena). Moreover, although the oil/water contrast decreases due to the time passed (approximately one week) from the first release of oil into the sea, it should be noted that, once again, RST completely prevents false detections.
Similar improvements were achieved by using the new RETIRA $_{\text {box }}$ index in the case of the Lebanon oil spill event occurring in July 2006, during the Lebanon war (UNEP, 2006). As an example, the results obtained for the AVHRR image of 24 July 2006 at 10.31 GMT (12.31 LT) are shown in Fig. 5. These results confirm that the proposed approach, also in its new updated version, is able to detect oil spill with high reliability (no false alarms over full scene) at high S/N levels $(>3)$ even in other geographic position and under different conditions (kind of oil, duration in time, wheatear condition, etc.).

Also in this case a detailed mapping was possible (Fig. 5c), investigating also lower intensity anomalies providing a better description of actual oil spill area extent and thickness. This analysis allowed us also to note that the detected anomalies are localized in the same area where the oil spill was independently (e.g. REMPEC, 2006; Coppini et al., 2010) mapped from in-situ and satellite observations made by optical (e.g. EOS-MODIS) and SAR (ENVISAT-ASAR) sensors with a noticeable correlation with the forecast made by models like CYCOFOS (http://www.oceanography.ucy. ac.cy/cycofos/forecast.html) for the same period.

\section{Conclusions}

In this paper an advanced configuration of the basic RST approach for near real-time detection and monitoring of oil spills by means of passive satellite sensors has been presented and discussed.

The comparison performed with results achieved by applying other AVHRR-based (including previous RST based) techniques confirmed evident improvements achievable with the new approach which save the same unique reliability (100\%, with zero false alarms), redoubling the number of oil-affected pixels identified for sure by contemporary increasing the $\mathrm{S} / \mathrm{N}$ at levels never reached before. A full comparison was made considering the case that occurred off the coast between Kuwait and Saudi Arabia in January 1991 

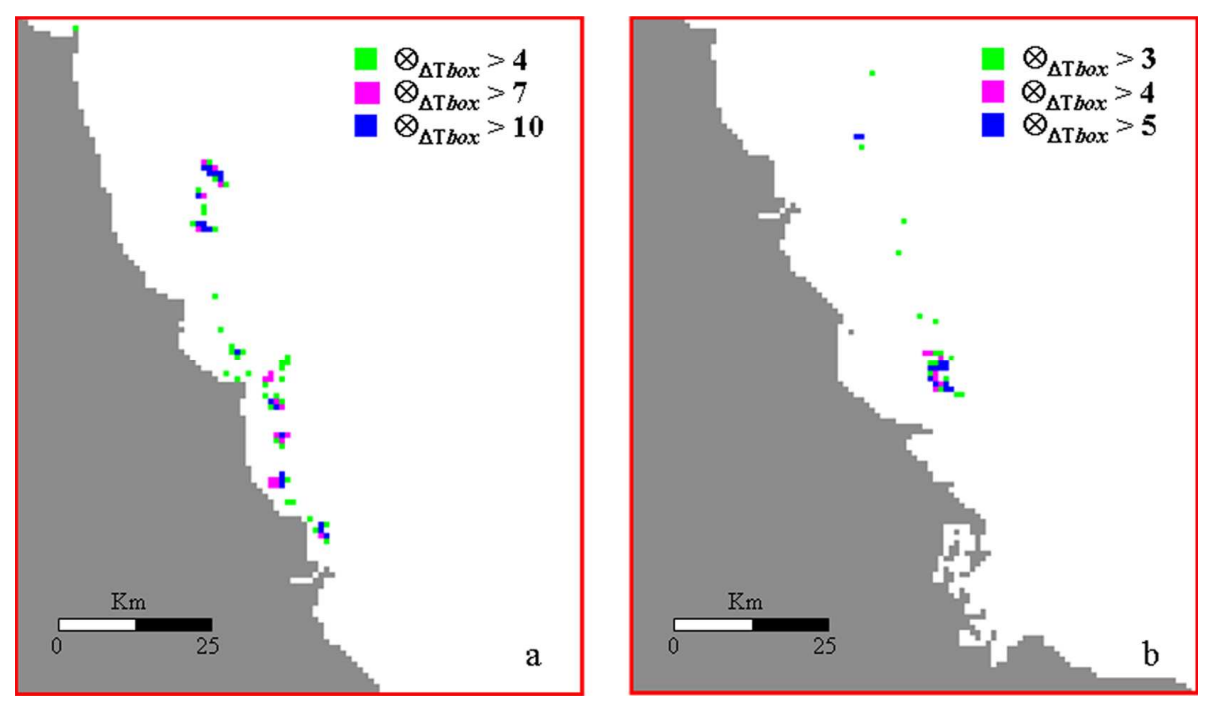

Fig. 4. Mapping of the oil spill structure exploiting different cutting S/N levels of RETIRA of Fig. 3d.
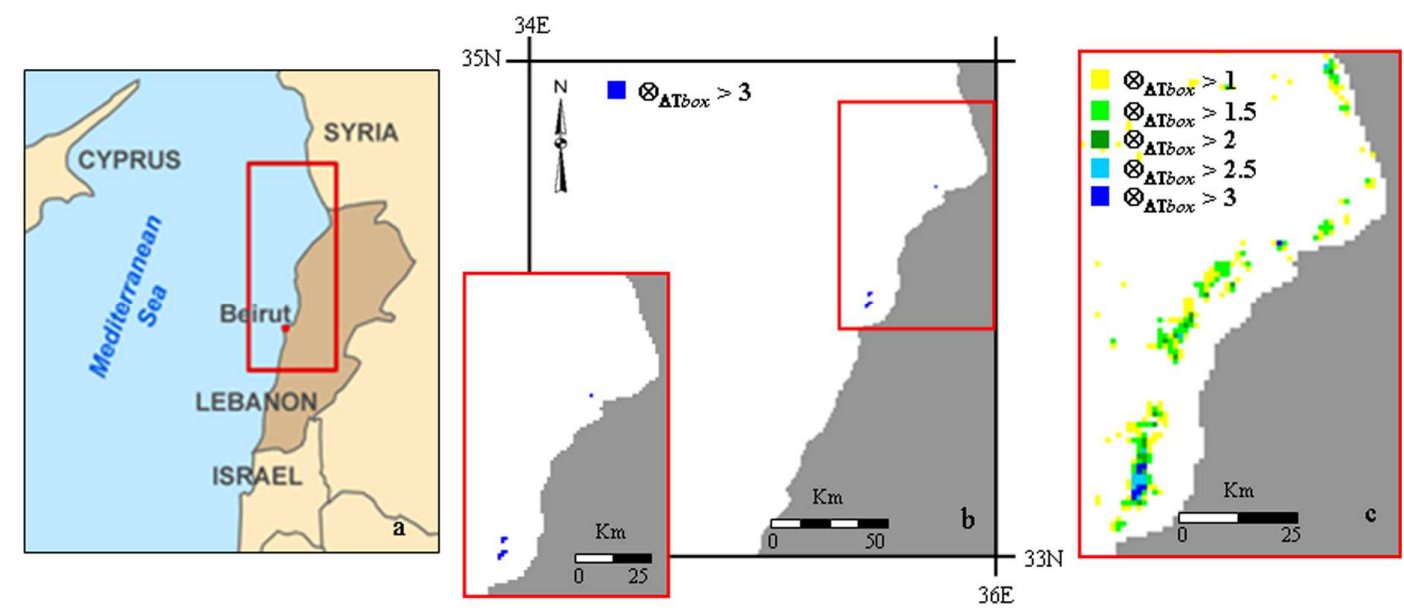

Fig. 5. Analysis of 2006 Lebanon oil spill event. (a) Area involved in the oil spill. (b) Identification for sure of the presence of an oil spill in the area by using RETIRA box index on the AVHRR image (TIR channel 5) collected on 24 July 2006 at 10:31 GMT (12:31 LT): oil spill affected pixels are depicted in blue, land is masked in gray and sea is white coloured; area indicated by red box is magnified in the

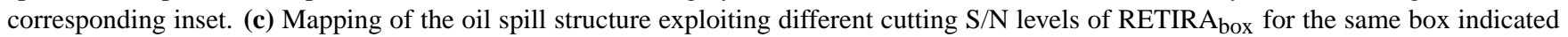
in (b).

during "the Gulf War", which has been confirmed by further analysis carried out on the case of oil release occurred during the Lebanon War, in July 2006.

In both cases, the advantages of the RST-based methods appear confirmed, even in this new configuration. In particular, also the approach proposed for the first time in this paper is completely automatic and based on sole satellite (and no other ancillary) data and is, thus, perfectly suitable for operational real-time application in whatever geographic context. Moreover, compared with other traditional techniques, whose results have been also shown in this work, it completely overcomes the problem of false alarms related to the normal dynamics of sea surface. Additionally, this study has demonstrated that the proposed technique is able to save oil spill detection capability also in the subsequent days of the event, when emulsion effects increase and may generally limit the efficiency of traditional oil mapping schemes. This enhanced, once more, the importance of using satellite data, especially those acquired from meteorological satellites which, despite their lowmedium spatial resolution, may assure (in absence of cloud cover) high observational frequency. In particular, also in the case of natural disasters, in order to mitigate the related environmental impacts, a timely alert and frequent 
updated information are essential. The proposed approach can guarantee these characteristics and so can become a useful tool in the management of such events.

Finally, the results achieved by this work confirmed not only the reliability of the RST approach in this new updated configuration, but also its full exportability to different geographic areas.

Moreover, the total independence of the proposed approach (like all the other RST-based techniques) from a specific satellite platform, allows it to be exported to different satellites and sensors. The present satellite sensors aboard weather platforms might then be profitably used to test the proposed approach with expected benefits coming from their improved spectral resolution. For example, MODIS (Moderate Resolution Imaging Spectroradiometer) aboard EOS satellites Terra and Aqua, could be seen as an AVHRR evolution. In fact, among its 36 bands in the optical region, several channels are very similar to those of AVHRR (for example MODIS bands 31 and 32 are comparable with AVHRR channel 4 and 5, respectively). The implementation of the proposed methodology also on MODIS thermal data will increase the observational frequency achievable by coupling AVHRR and MODIS passes. Moreover, the good spatial resolution of Visible and Near-Infrared (VNIR) MODIS channels ( $250 \mathrm{~m}$ in both channels 1 and 2) and the different spectral signatures of oil and seawater in VNIR region, might be exploited to try to improve the mapping capability of the proposed technique.

Furthermore, the SEVIRI (Spinning Enhanced and Visible Infrared Imager) on board the MSG (Meteosat Second Generation), having 12 spectral channels (6 of them similar to AVHRR and MODIS) and an observational frequency of 15 min, could guarantee a general improvement in terms of monitoring capability and an excellent opportunity for RSTbased techniques. In fact, geostationary platforms can assure a significant reduction of observational noise because of geostationary attitude (same view-angle, natural co-location of images, constant daily acquisition times, etc.), with a consequent further improvement in terms of sensitivity. Such an advantage, combined with the very high temporal resolution offered by SEVIRI, may actually contribute to the development of a highly effective space system for timely detection and continuous monitoring of oil spills, even of relatively small size and extent. The results obtained so far encourage the investigation of the possible implementation of the RST approach on MSG-SEVIRI for the abovementioned reasons. Although issues possibly related to the coarse spatial resolution of geostationary platforms (3-4 km) should be carefully investigated, the very high signal-tonoise ratios (already found by polar platforms, and expected to be further improved by using geostationary ones) strongly suggest investing in the near future in this direction, and looking at a real-time satellite system for oil spill detection and monitoring. Finally, the integration of such a system with the present and future performances offered by SAR technology, in the frame of a multi-sensor approach and strategy, should be also seriously considered in order to further improve our observing capability from space and to build an actually effective and efficacious support system to better manage marine and coastal environments.

This is also the experience gained with projects like MOON (Mediterranean Operational Oceanography Network, http://www.moon-oceanforecasting.eu) whose forecasts, in the case of the Lebanon event of July 2006 have been found in very close agreement with the results reported in this paper.

It should be mentioned, in conclusion, that reliable data analysis methods and integrated observation systems (like the one mentioned in this paper) can be of strategic use in whatever oil spill accident and in particular for those related to or directly caused by natural hazards (or by other natural phenomena like "seepages"), when the occurrence of such kind of events is much more unpredictable and suitable timely alert systems become critical in reducing negative impacts on the environment.

Edited by: E. Krausmann

Reviewed by: two anonymous referees

\section{References}

ASI (Italian Space Agency): COSMO-SkyMed System Description \& User Guide, 49 pp, available at: http://www.cosmo-skymed.it/ it/index.htm, 2007.

Baldassarre, G., Benigno, G., Corrado, R., Coviello, I., Filizzola, C., Lacava, T., Marchese, F., Mazzeo, G., Paciello, R., Pergola, N., Sannazzaro, F., Serio, S., and Tramutoli, V.: Assessment of the Robust Satellite Technique (RST) in real time detection of summer fires. Proceedings of Multitemp 2009, Fifth International Workshop on the Analysis of Multitemporal Remote Sensing Images, Mistic, Connecticut, USA, 28-30 July 2009, 216-223, 2009.

Bonfiglio, A., Macchiato, M., Pergola, N., Pietrapertosa, C., and Tramutoli, V.: AVHRR Automated detection of volcanic clouds, Int. J. Remote Sens., 26(1), 9-27, 2005.

Borzelli, G., Ulivieri, C., Ciappa, A., Antonelli, G., and Laneve, G.: A new perspective on oil slick detection from space by NOAA satellites. Int. J. Remote Sens., 17(7), 1279-1292, 1996.

Brekke, C. and Solberg, A. H. S.: Review on Oil spill detection by satellite remote sensing, Remote Sens. Environ., 95, 1-13, 2005.

Casciello, D., Lacava, T., Pergola, N., and Tramutoli, V.: Robust Satellite Techniques (RST) for Oil Spill Detection and Monitoring, in: Proceedings of MultiTemp 2007, Fourth International Workshop on the Analysis of Multitemporal Remote Sensing Images, Leuven, Belgium, 18-20 July 2007, doi:10.1109/MULTITEMP.2007.4293040, 2007a.

Casciello, D., Grimaldi, C. S. L., Coviello, I., Lacava, T., Pergola, N., and Tramutoli, V.: A Robust Satellite Techniques for oil spill detection and monitoring in the optical range, in: Global Monitoring for Security and Stability (GMOSS), JRC Scientific 
and Technical Reports, edited by: Zeug, G. and Pesaresi, M., EUR 23033 EN, 294-305, 2007b.

Casciello, D., Lacava, T., Pergola, N., and Tramutoli, V.: Robust Satellite Techniques (RST) for oil spill detection and monitoring using AVHRR Thermal Infrared bands, Int. J. Remote Sens., in press, 2011.

Coppini, G., De Dominicis, M., Zodiatis, G., Lardner, R., Pinardi, N., Santoleri, R., Colella, S., Bignami, F., Hayes, D. R., Soloviev, D., Georgiou, G., and Kallos, G.: Hindcast of oil-spill pollution during the Lebanon crisis in the Eastern Mediterranean, July-August 2006, Mar. Pollut. B., doi:10.1016/j.marpolbul.2010.08.021, 2010.

Corrado, R., Caputo, R., Filizzola, C., Pergola, N., Pietrapertosa, C., and Tramutoli, V.: Seismically active area monitoring by robust TIR satellite techniques: a sensitivity analysis on low magnitude earthquakes in Greece and Turkey, Nat. Hazards Earth Syst. Sci., 5, 101-108, doi:10.5194/nhess-5-101-2005, 2005.

Cross, A. M.: Monitoring marine oil pollution using AVHRR data: observation off coast of Kuwait and Saudi Arabia during January 1991, Int. J. Remote Sens., 13, 781-788, 1992.

Cruz, A. M. and Krausmann, E.: Damage to offshore oil and gas facilities following Hurricanes Katrina and Rita: An overview, J. Loss Prevent. Proc., 21, 620-626, 2008.

Cruz, A. M. and Krausmann, E.: Hazardous-materials releases from offshore oil and gas facilities and emergency response following Hurricanes Katrina and Rita, J. Loss Prevent. Proc., 22 59-65, 2009.

Cuomo, V., Lasaponara, R., and Tramutoli, V.: Evaluation of a new satellite-based method for forest fire detection, Int. J. Remote Sens., 22(9), 1799-1826, 2001.

Daniel, P. and Potevin, J.: A numerical study of movements of an oil slick on the sea surface in the Persian Gulf from 25 January 1991 to 1 February 1991, in: Proceedings of the First Thematic Conference on Remote Sensing for Marine and Coastal Environments, ERIM, 249-260, 1992.

Di Bello, G., Filizzola, C., Lacava, T., Marchese, F., Pergola, N., Pietrapertosa, C., Piscitelli, S., Scaffidi, I., and Tramutoli, V.: Robust Satellite Techniques for Volcanic and Seismic Hazards Monitoring, Ann. Geophys., 47(1), 49-64, 2004.

e-GEOS press release: Fourth satellite of the COSMO-SkyMed constellation launched successfully, available at: http://www. e-geos.it/news/10-11-06-CSK-4/news-10-11-06.html, 2010.

Faruolo, M., Coviello, I., Lacava, T., Pergola, N., and Tramutoli, V.: Real Time Monitoring of flooded areas by a multi-temporal analysis of optical satellite data, in: Proceedings of Geoscience and Remote Sensing Symposium, 2009 IEEE International, IGARSS 2009, Cape Town, South Africa, 13-17 July 2009, 4, 192-195, doi:10.1109/IGARSS.2009.5418299, 2009.

Ferraro, G., Bernardini, A., David, M., Meyer-Roux, S., Muellenhoff, O., Perkovic, M., Tarchi, D., and Topouzelis, K.: Towards an operational use of space imagery for oil pollution monitoring in the Mediterranean basin: A demonstration in the Adriatic Sea, Mar. Pollut. Bull., 54, 403-422, 2007.

Filizzola, C., Pergola, N., Pietrapertosa, C., and Tramutoli, V.: Robust satellite techniques for seismically active areas monitoring: a sensitivity analysis on September 7, 1999 Athens's earthquake, Phys. Chem. Earth, 29, 517-527, 2004.

Filizzola, C., Lacava, T., Marchese, F., Pergola, N., Scaffidi, I., and Tramutoli, V.: Assessing RAT (Robust AVHRR Techniques) performances for volcanic ash cloud detection and monitoring in near realtime: The 2002 eruption of Mt. Etna (Italy), Remote Sens. Environ., 107, 440-454, 2007.

Fingas, M. F. and Brown, C. E.: Remote sensing of oil spills, Sea Technol., 38, 37-46, 1997.

Fingas, M. F. and Brown, C. E.: A review of the status of advanced technologies for the detection of oil in and with ice, Spill Sci. Technol. B., 6(5), 295-302, 2000.

Genzano, N., Aliano, C., Filizzola, C., Pergola, N., and Tramutoli, V.: A robust satellite technique for monitoring seismically active areas: The case of Bhuj-Gujarat earthquake, Tectonophysics, 431, 197-210, 2007.

Genzano, N., Aliano, C., Corrado, R., Filizzola, C., Lisi, M., Mazzeo, G., Paciello, R., Pergola, N., and Tramutoli, V.: RST analysis of MSG-SEVIRI TIR radiances at the time of the Abruzzo 6 April 2009 earthquake, Nat. Hazards Earth Syst. Sci., 9, 2073-2084, doi:10.5194/nhess-9-2073-2009, 2009.

Grimaldi, C. S. L., Coviello, I., Lacava, T., Pergola, N., and Tramutoli, V.: Near real time oil spill detection and monitoring using satellite optical data, in: Proceedings of Geoscience and Remote Sensing Symposium, 2009 IEEE International, IGARSS 2009, Cape Town, South Africa, 13-17 July 2009, 4, 709-712, doi:10.1109/IGARSS.2009.5417590, 2009.

Hogarth, W.: Testimony on the Effects of Hurricanes Katrina and Rita on the Fishing Industry and Fishing Communities in the Gulf of Mexico before the House Committee on Resources, Subcommittee on Fisheries and Oceans, available at: http://www. ogc.doc.gov/ogc/legreg/testimon/109f/hogarth1215.htm (last access: 17 December 2010), December 2005.

Howari, F. M.: Investigation of hydrocarbon pollution in the vicinity of United Arab Emirates coasts using visible and near infrared remote sensing data, J. Coastal. Res., 20(4), 1089-1095, 2004.

Hu, C., Müller-Krager, F. E., Taylor, C. J., Myhre, D., Murch, B., Odriozola, A. L., and Godoy G..: MODIS detects oil spills in Lake Maracaibo, Venezuela, EOS T. Am. Geophys. Un., 84(33), 313-319, 2003.

ITOPF (International Tanker Owners Pollution Federation Limited): Handbook 2010/2011, available at: http: //www.itopf.com/information-services/publications/documents/ itopfhandbook2010.pdf, 2010.

Jha, M. N., Levy, J., and Gao, Y.: Advances in Remote Sensing for Oil Spill Disaster Management: State-of-the-Art Sensor Technology for Oil spill Surveillance, Sensors, 8, 236-255, 2008.

Kostianoy, A., Litovchenko, K., Lavrova, O., Mityagina, M., Bocharova, T., Lebedev, S., Stanichny, S., Soloviev, D., Sirota, A., and Pichuzhkina O.: Operational Satellite Monitorino of Oil Spill Pollution in the Southeastern Baltic Sea: 18 Months Experience, Environ. Eng. Manag. J., 4(38), 70-77, 2006.

Lacava, T., Cuomo, V., Di Leo, E. V., Pergola, N., Romano, F., and Tramutoli, V.: Improving Soil Wetness Variations Monitoring From Passive Microwave Satellite Data: The Case Of April 2000 Hungary Flood, Remote Sens. Environ., 96(2), 135-148, 2005.

Lacava, T., Di Leo, E. V., Pergola, N., and Tramutoli, V.: Spacetime soil wetness monitoring by a multi-temporal microwave satellite records analysis, Phys. Chem. Earth, 31, 1274-1283, 2006. 
Lacava, T., Di Leo, E. V., Pergola, N., and Tramutoli, V.: Monitoring soil wetness variation by a multi-temporal passive microwave technique, in: Proceedings of MultiTemp 2007, Fourth International Workshop on the Analysis of Multitemporal Remote Sensing Images, Leuven, Belgium, 18-20 July 2007, doi:10.1109/MULTITEMP.2007.4293043, 2007.

Lacava, T., Calice, G., Coviello, I., Pergola, N., and Tramutoli, V.: Advanced multi-temporal passive microwave data analysis for soil wetness monitoring and flood risk forecast, in: Proceedings of Geoscience and Remote Sensing Symposium, 2009 IEEE International, IGARSS 2009, Cape Town, South Africa, 1317 July 2009, 3, 490-493, doi:10.1109/IGARSS.2009.5418299, 2009.

Lacava, T., Brocca, L., Calice, G., Melone, F., Moramarco, T., Pergola, N., and Tramutoli, V.: Soil moisture variations monitoring by AMSU-based soil wetness indices: a longterm inter-comparison with ground measurements, Remote Sens. Environ., 114(10), 2317-2325, doi:10.1016/j.rse.2010.05.008, 2010a.

Lacava, T., Pergola, N., Sannazzaro, F., Tramutoli, V.: Improving flood monitoring by the Robust AVHRR Technique (RAT) approach: the case of the April 2000 Hungary flood, Int. J. Remote Sens., 31(8), 2043-2062, 2010b.

Lisi, M., Filizzola, C., Genzano, N., Grimaldi, C. S. L., Lacava, T., Marchese, F., Mazzeo, G., Pergola, N., and Tramutoli, V.: A study on the Abruzzo 6 April 2009 earthquake by applying the RST approach to 15 years of AVHRR TIR observations, Nat. Hazards Earth Syst. Sci., 10, 395-406, doi:10.5194/nhess-10395-2010, 2010.

Liu, A. K., Wu, S. Y., Tseng, W. Y., and Pichel, W. G.: Wavelet analysis of SAR images for coastal monitoring, Can. J. Remote. Sens., 26, 494-500, 2000.

Mazzeo, G., Marchese, F., Filizzola, C., Pergola, N., and Tramutoli, V.: A Multi-temporal Robust Satellite Technique (RST) for forest fire detection, in: Proceedings of Multitemp 2007, Fourth International Workshop on the Analysis of Multitemporal Remote Sensing Images, Leuven, Belgium, 18-20 July 2007, doi:10.1109/MULTITEMP.2007.4293060, 2007.

Mitsch, W. J.: The 2010 oil spill in the Gulf of Mexico: What would Mother Nature do?, Ecol. Eng., 36 1607-1610, 2010.

Pergola, N., Tramutoli, V., Lacava, T., and Pietrapertosa, C.: Robust satellite techniques for monitoring volcanic eruptions, Ann. Geophys., 45(2), 167-177, 2001.

Pergola, N., Tramutoli, V., Scaffidi, I., Lacava, T., and Marchese, F.: Improving volcanic ash clouds detection by a robust satellite technique, Remote Sens. Environ., 90(1), 1-22, 2004a.

Pergola, N., Tramutoli, V., and Marchese, F.: Automated detection of thermal features of active volcanoes by means of Infrared AVHRR records, Remote Sens. Environ., 93(3), 311-327, $2004 \mathrm{~b}$.

Pergola, N., D’Angelo, G., Lisi, M., Marchese, F., Mazzeo, G., and Tramutoli, V.: Time domain analysis of robust satellite techniques (RST) for near real-time monitoring of active volcanoes and thermal precursor identification, Phys. Chem. Earth, 34(6-7), 380-385, 2009.
Pine, J.: Hurricane Katrina and Oil Spills: Impact on Coastal and Ocean Environments, Oceanography, 19(2), 37-39, June 2006.

Proctor, R., Flather, R. A., and Elliott, A. J.: Modelling tides and surface drift in the Arabian Gulf application to the Gulf oil spill, Cont. Shelf Res., 14(5), 531-545, 1994.

REMPEC (Regional Marine Pollution Emergency Response Center for the Mediterranean Sea): "SITREP 1 SPILL IN LEBANON", Situation Report, available at: http://www.rempec. org/newsmore. asp?id=153\\&lang=en, 2006.

Shi, L., Zhang, X., Seielstand, G., Zhao, C., and He, M.: Oil spill detection by MODIS images using Fuzzy Cluster and Texture Feature Extraction, IEEE Oceans 07, Aberdeen, UK, 18-21 June 2007.

Schmidt Etkin, D.: Spill Occurrences: A World Overview, Chapter 2, in: Oil spill science and technology: prevention, response, and clean up, 1st edn., edited by: Fingas, M., Elsevier, 7-48, doi:10.1016/B978-1-85617-943-0.10002-4, 2011.

Tramutoli, V.: Robust AVHRR Techniques (RAT) for Environmental Monitoring: theory and applications, in: Earth Surface Remote Sensing II, edited by: Cecchi, G. and Zilioli, E., Proceedings of SPIE, 3496, 101-113, 1998.

Tramutoli, V.: Robust Satellites Techniques (RST) for natural and environmental hazards monitoring and mitigation: ten years and applications, in: Proceedings of The 9th International Symposium on Physical Measurements and Signatures in Remote Sensing, ISPRS, Beijing, China, vol. XXXVI(7/W20), 792-795, ISSN 1682-1750, 2005.

Tramutoli, V.: Robust Satellite Techniques (RST) for Natural and Environmental Hazards Monitoring and Mitigation: Theory and Applications, in: Proceedings of Multitemp 2007, Fourth International Workshop on the Analysis of Multitemporal Remote Sensing Images, Louven, Belgium, 18-20 July 2007, doi:10.1109/MULTITEMP.2007.4293057, 2007.

Tramutoli, V., Di Bello, G., Pergola, N., and Piscitelli, S.: Robust satellite techniques for remote sensing of seismically active areas, Ann. Geophys., 44(2), 295-312, 2001.

Tramutoli, V., Cuomo, V., Filizzola, C., Pergola, N., and Pietrapertosa, C.: Assessing the potential of thermal infrared satellite surveys for monitoring seismically active areas: The case of Kocaeli (İzmit) earthquake, August 17, 1999, Remote Sens. Environ., 96, 409-426, 2005.

Tseng, W. Y. and Chiu, L. S.: AVHRR Observations of Persian Gulf Oil Spills, in: Proceeding of Geoscience and Remote Sensing Symposium, IGARSS 1994, Pasadena, California, August 8-12 1994, 2, 779-782, doi:10.1109/IGARSS.1994.399259, 1994.

UNEP (United Nations Environment Programme): "Environmental Update No. 01 - Lebanon Crisis - 27 July 2006", available at: http://www.unep.org/lebanon/pdfs/EESUpdate4-27July.pdf, 2006.

WCMC (World Conservation Monitoring Centre): Gulf war environmental information service: impact on the marine environment, available at: http://www.unep-wcmc.org/latenews/ Gulf_war1991/Gulf.pdf, 1991. 